\title{
EFFECT OF ZOTEPINE ON AFTERDISCHARGE INDUCED BY ELECTRICAL STIMULATION OF AMYGDALOID NUCLEUS IN RATS
}

\author{
Hisashi SATOH, Kyoichi SHIMOMURA and Jo MOR| \\ Research Laboratories. Fujisavva Fharmaceutical Co. Ltd., \\ Yodogawa-ku, Osaka 532. Japan
}

Accepted November 16, 1981

Zotepine (2-chloro-11-(2-dimethyl-amino -ethoxy)-dibenzo $[b, f]$ thiepin) is a new neuroleptic drug. synthesized in the Research Laboratories of Fujisawa Pharmaceutical Co. Ltd. Zotepine is characterized by a weak extrapyramidal effect in humans $(1,2)$. In animal studies zotepine had a stronger antiserotonergic activity than other neuroleptic drugs (3), although its anti-dopaminergic activity is the same as that of chlorpromazine (4). One of the side effects of neuroleptic drugs is the occasional induction of seizure in schizophrenics (5), but the effect of zotepine on seizure has not been examined. Afterdischarge induced by electrical stimu lation of the limbic system is reported to be a good model for assessing the clinical effect of a drug on seizure, and it is reported to be potentiated by neuroleptic drugs such as chlorpromazine in rats (6) and rabbits (7. 8). In the present experiment, we examined the comparative effects of zotepine and chlorpromazine on afterdischarge induced by electrical stimulation of the amygdaloid nucleus in rats.

Male Wistar rats used weighed about $200 \mathrm{~g}$ at the time of electrode implantation. Rats anaesthesized with pentobarbital $-\mathrm{Na}(50 \mathrm{mg} /$ kg. i.p.) were placed in a stereotaxic apparatus and were implanted with twisted stainless steel wire electrodes in the cerebral cortex (A: 6.9. L: 3.0), amygdaloid nucleus (A: 5.0. L: 4.5. H: -3.0 ), and hippocampus (A: $3.0, L: 2.5, H: 2.0$ ), according to De
Groot (9). Groups of five rats were used for the recording of electroencephalograms by bipolar electrodes on an electroencephalograph (Nihon Kohden, ME-135D) about 10 days after implantation. Afterdischarge was produced by electrical stimulation of the amygdaloid nucleus with rectangular pulse waves (2-4 V, $40 \mathrm{~Hz}, 3 \mathrm{msec}$ ) delivered by an electric stimulator (San-ei Sokki, ES-103). and the duration of stimulation was 3 sec. Electrical stimulation of the amygdaloid nucleus and recording of afterdischarge were repeated 2 times at $1 \mathrm{hr}$ intervals before dosing with the test drugs. Only those rats which showed almost the same duration of afterdischarge in the two trials were used in the experiment. Soon after the second trials, rats were given zotepine or chlorpromazine, and $20 \mathrm{~min}$ after dosing. the amygdaloid nucleus was stimulated.

Drugs used were zotepine and chlorpromazine hydrochloride (synthesized in our research laboratories). Zotepine was dissolved in a minimum amount of $1 \mathrm{~N} \mathrm{HCl}$. adjusted to $\mathrm{pH} 7$ with $1 \mathrm{~N} \mathrm{NaOH}$, and diluted with saline to the desired concentration. Chlorpromazine was dissolved in saline. Both drugs were given I.v in a volume of $5 \mathrm{ml} / \mathrm{kg}$ body weight.

Afterdischarge was induced in the cerebral cortex, amygdaloid nucleus, and hippocampus immediately after electrical stimulation of the amygdaloid nucleus (first afterdischarge). Occasionally, one or more 


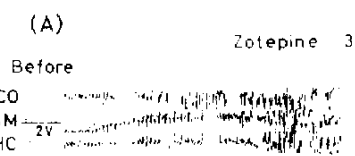

20 sec
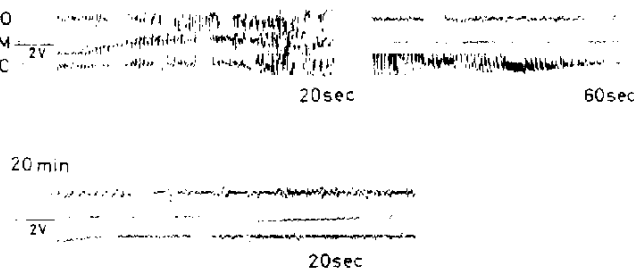

(B)
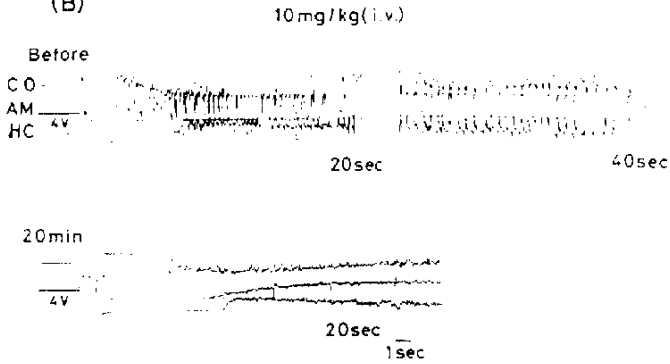

Fig. 1. Effect of zotepine, $3.2 \mathrm{mg} / \mathrm{kg}(A)$ and 10 $\mathrm{mg} / \mathrm{kg}(B)$. on afterdischarge in rats. The amygdaloid nucleus was stimulated electrically ( $4 \mathrm{~Hz}, 2-4 \mathrm{~V}, 3 \mathrm{msec}$ ) at the point indicated by the bar. Zotepine was given i.v. 20 min before the stimulation. Zotepine strongly inhibited the afterdischarge at both doses. $\mathrm{CO}$ : cerebral cortex. AM: amygdaloid nucleus, HC: hippocampus.

weak afterdischarges ensued after the disappearance of the first ones (second afterdischarge). At a dose of $1 \mathrm{mg} / \mathrm{kg}$. zotepine and chlorpromazine had no effect on the afterdischarge. At a cose of $3.2 \mathrm{mg} / \mathrm{kg}$. zotepine shortened the duration of afterdischarge in three of five rats when compared with that before dosing. The result is shown in Fig. 1. In the other two rats, zotepine produced no effect. In cantrast. chlorpromazine produced 40 and $200 \%$ prolongation of the duration of afterdischarge in two of five rats at a dose of $3.2 \mathrm{mg} / \mathrm{kg}$ (Fig. 2). In one rat, a second afterdischarge which was not seen before dosing was induced after dosing with $3.2 \mathrm{mg} / \mathrm{kg}$ chlorpromazine. In the other two rats. afterdischarge was not affected. At a dose of $10 \mathrm{mg} / \mathrm{kg}$. zotepine shortened the duration
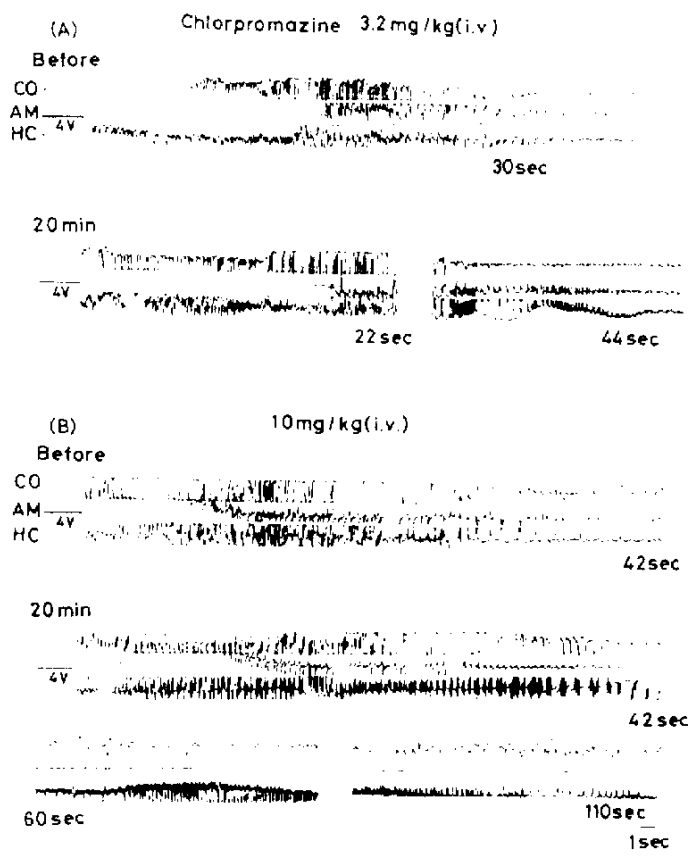

Fig. 2. Effect of chlorpromazine, $3.2 \mathrm{mg} / \mathrm{kg}(\mathrm{A})$ and $10 \mathrm{mg} / \mathrm{kg}(\mathrm{B})$, on afterdischarge in rats. The amygdaloid nucleus was stimulated electrically (4 Hz, 2-4 V. $3 \mathrm{msec}$ ) at the point indicated by the bar. Chlorpromazine was given i.v. 20 min before the stimulation. Chlorpromazine enhanced the afterdischarge at both doses. In the case of $B$, a second afterdischarge was provoked. CO: cerebral cortex. AM: amygdaloid nucleus, HC: hippocampus.

of afterdischarge in all the rats by 50 to $100 \%$ (Fig. 1). In contrast chlorpromazine in a dose of $10 \mathrm{mg} / \mathrm{kg}$ prolonged the duration of afterdischarge by $50 \%$ in two of the five rats. produced a newly provoked second afterdischarge in one rat (Fig. 2), and had no effect in the other two rats.

The prolonging effect of chlorpromazine on the duration of afterdischarge has already been reported in rats $(6)$ and rabbits $(7,8)$. Killam et al. (10) and Schallek et al. (11) have also reported that chlorpromazine reduced significantly the threshold of amygdaloid afterdischarge. Our findings on chlorpromazine agree with these reports. It is interesting that zotepine, unlike chlor- 
promazine, shortened the duration of afterdischarge in the cerebral cortex, amygdaloid nucleus, and hippocampus. The mechanism of action of zotepine lies in its elevation of the seizure threshold in the amygdaloid nucleus rather than in the depression of impulse conduction from the amygdaloid nucleus to the other sites of the brain because the afterdischarge in the amygdaloid nucleus was inhibited after zotepine, but not after chlorpromazine. Though the mechanism of afterdischarge is unclear, it is known that effects of drugs on afterdischarge are related to their clinical epileptic effects. Therefore, there is a possibility that zotepine is clinically less epileptic than chlorpromazine.

\section{REFERENCES}

1) Amamoto, H. and Gotoh, T: Clinical study of zotepine, a new neuroleptic drug. The Clinical Report 14, 1660-1682 (1980) (in Japanese)

2) Tanaka, M., Tanaka, I. and Maeda, S.: Effects of zotepine in schizophrenics. The Clinical Report 14, 1684-1704 (1980) (in Japanese)

3) Lai, H., Carino, M.A. and Horita, A.: Antiserotonin properties of neuroleptic drugs. In Psychopharmacology and Biochemistry of Neurotransmitter Receptors. Edited by Yamamura, H., Olsen, R.M. and Usdin. E., p. 347-353, Elsevier North Holland. Amsterdam (1980)

4) Uchida, S., Honda, F., Otsuka, M., Satoh, Y.,
Mori, J., Ono, T. and Hitomi, M.: Pharmacological study of (2-chloro-11-(2-dimethyl -aminoethoxy)-dibenzo [b.f]thiepin) (zotepine) a new neuroleptic drug. Arzneim. Forsch. 29 1588-1594 (1979)

5) Ayd, F.J., Jr.: Clinical use of phenothiazino derivatives in psychiatric office practice. In Psychosomatic Medicine. The First Hahnemann Synposium, Edited by Nordine. J.H. and Moyer. J.H., p. 471-475, Lea Febiger, Philadelphia (1962)

6) Kamei, C., Masuda, Y., Oka, M. and Shimizu, M.: Effects of antidepressant drugs on amygdaloid after-discharge in rats. Japan $J$. Pharmacol. 25, 359-365 (1975)

7) Watanabe, S., Nishi, H. and Ueki, S.: Electroencephalographic effects of hydroxyzine hydrochloride (Atarax) in rabbits. Folia pharmacol. japon. 70, 19-37 (1974) (Abs, in English)

8) Watanabe, S., Kawasaki, H. and Ueki, S.: Electroencephalographic effects of maprotiline, a new antidepressant. in rabbits. Folia pharmacol. japon. 70, 767-784 (1974) (Abs. in English)

9) De Groot, J.: The rat brain in stereotaxic coordinates. Verh. K. Ned Acad. Wet. 52, 14-39 (1959)

10) Killam, E.K., Killam, K.F. and Shaw, T.: The effects of psychotherapeutic compounds on central afferent and limbic pathways. Ann. N.Y. Acad. Sci. 66, 784-805 (1957)

11) Schallek, W. Zabransky, F. and Kuehn, A.: Effects of benzodiazepines on central nervous system of cat. Archs int. Pharmacodyn. Thér. $149,467-483(1964)$ 